\title{
Stock Market Development And Economic Growth: Evidence From Pakistan
}

\author{
MUHAMMAD KAMRAN \\ Lecturer, City University of Science \& Informaion Technology, Peshawar \\ DR. MUHAMMAD ZAHID \\ Assistant Professor, City University of Science \& Informaion Technology, \\ Peshawar \\ SAID WALI \\ Lecturer, City University of Science \& Informaion Technology, Peshawar \\ KAMRAN RIZWAN \\ Research Student MBA (1.5), City University of Science \& Informaion Technology, \\ Peshawar
}

\begin{abstract}
The key motive of this research is to explore the role of stock markets in economic growth in Pakistan for the span of 2000 to 2017 by using the Ordinary Least Square $(O L S)$ and fully Modified Ordinary Least Square approach (FMOLS). The research explored the stock market development and economic growth association by employing the two significant measures of the stock market development, that is the size (DSIZE) and liquidity (DLIQ) of the market accompanied with Foreign Direct Investment (DFDI) and Stock Market Capitalization (DSMC). The outcomes reveal that the included independent variables have a positive effect on the dependent variable $i$. e. DGDP except for liquidity which has no significant effect on DGDP. It is expected that the findings of the investigation can be utilized by the government for destined follow-up and reassessment of economic development programs in Pakistan. The influential policy suggestion was the attraction of the Foreign Direct Investment and trade openness by exploring their major determinants and also focus on the positive relationship variables.
\end{abstract}

Keywords: FMOLS, OLS, GDP

\section{Introduction}

The essence of the financial market is always there when researcher measures the soundness of economic growth; it plays the role of a pillar and as significant index in the economy. This predicts that there is necessarily a link with the economy. Bagehot (1873) discloses that finance has a key function in the growth of the economy. The findings of Goldsmith (1969), McKinnon (1973) and Shaw (1973) imply that financial system executes a pivotal function in the growth of the economy. Being the significant component of the GDP, the equity market has an important function in the development of the industry and commerce that at last influence the economic growth of a state to a considerable range. The stock market is equally important for investors and industry 
both perspective. Reported by Levine and Zervos (1998) certain factors are there in the stock market which can be incorporated as a measurement that is why most of the financial personals the sectors and within a country keep checks on the ups and downs of the stock market from the past few decades. It is undertaken that soulful and certain stock market can energize rate of growth in the economy. Apart from smoothing the growth of the economy, the stock market plays the role of a lever for the growth in sectors, subsectors, industries, firms, and commerce which lastly promote the growth of the economy of a country up to certain extent.

According to Pakistan stock Exchange research report (2016) Pakistan's economy has affected by the bearish market for decades, from minor foreign investment, excluding for rare years of recent decades, this exceeds the lack of exports and imports as well as an undependable monetary shortfall, enormous inflation and unhealthy funds of foreign exchange. On another side Pakistan Stock Exchange (PSX) which is a major as well as high liquidity stock exchange in Pakistan that announced the best performing stock market in 2002. PSX started work from 1947 right afterward two months of partition. From January 2012 to April 2014 the KSE100 index is up by 155 percent of 11,348 to 28,913 points.

On 11 January 2016 all of these three stock exchanges were consolidated into Pakistan Stock Exchange Limited (PSX). Pakistan Stock Exchange (PSX) delivers a certain, sequential, liquid and potent digitized marketplace where investors can trade in stocks with other investments papers in available companies. For over 6 decades the exchange helps in running smoothly and more effectively the capital formation, serving a larger number of shares, including individuals and institutional investors, the trading community and companies that are listed. The stock markets of the globe performed will in the previous period but Pakistan stock market has excellent performance in the last year in highly liquid and large stock markets in the world entailing USA, Japan, Singapore, UK, Hong Kong China and India. In 2013 to 2014 the KSE-100 index displayed greater than $37 \%$ development and placed at peak as equated to the influential local and international stock markets.

The stock market has a pivotal function of the capital market, it affects the economy is a captious and important subject in modern economics. Financial markets make aneffective difference in minimizing the instability, expenses of a region with providing it with the fruitful exercises and hold on the market uncertainty, therefore those countries who need to better their prosperity they move to the development of their stock market. The stock market has a pivotal place in the capital market, in modern economics it aids in captious consequences to the economy. The stock market approves the phenomenon that financial markets are taking part in reducing the costs and frictions of the region by providing it the quality operation and maintaining the market stability, so it is important for a growth in a country to support and give pivotal place to the stock market.

The present examination taking into account the four dominant variables of the stock market expansion which are the size, liquidity, stock market capitalization and foreign direct investment. Theoretically, these market measures are looking forward to beingfavourably associated with the capability to bring funds and reduce uncertainty together on an economy-wide basis. Liquidity is the capability of a 
market to accommodate enough, high capacity of stock trades without seriously influencing the price. "Market capitalization is the value of outstanding shares of a company calculated by multiplying the current stock price and outstanding shares," foreign direct investment is an investment from a company (usually companies rather than government) of one country into another country that effect to establish operations or to acquire assets, including concern in other businesses.

\subsection{Problem Statement}

The research investigated the causal relationship between stock market and in economic growth for Pakistan for the period 2000-2015 using Fully Modified Ordinary Least Square.

\subsection{Research Questions}

Research questions of the study are:

- Is there a significant role of the stock market in the economic growth?

- How does stock market development affect the Economic growth with special reference to the growth of Pakistan's Stock Market?

\section{Research Objectives}

The research objectives of the study are:

- To investigate that is there a significant relationship exists between stock market development and economic growth of Pakistan.

- To identify the dimension of correlation between stock market development and economic growth.

\section{Literature Review}

The broad literature indicates the significance of the stock market performance in the improvement of economic conditions. Is it possible the new stock market maximizes economic growth? Greenwood and Jovanovic (1990) and King and Levine (1993) display that new stock markets give correct knowledge and well-timed to the investors, which in turn maximize the risk-adjusted returns. Moreover, North (1991) suggested that developing stock exchange may lessen the expenditure of shifting the ownership, which is a motive to investor's interest to infuse in equity markets and can higher the economic growth.

\subsection{Gross Domestic Product (GDP)}

Multiple studies have given both negative and positive results of the stock market development and the economic growth. Mishkin (2001) asserted that a skillfullyplanned and arranged stock market will give chances of investment in a country which become thereasons of productive projects and programs and at last give the results in the form of better economic activity and avoiding the risk and providing the capital in an effective manner. Liquidity measurement was described as a mean to conclude the capability of the stock market to deal with the higher amount of traded stock, without concerning of deviation in the price levels. Shahbaz et al. (2008) asserted a lengthy period relation amid equity market progression and economic expansion in the context of Pakistan. The previous researches conclusions were vigorous as well as sound and the researchers show that the stock market development was a pivotal factor in economic progression. Researchers used the Engle-Granger causality assessments which assure the availability of bidirectional causality between equity markets progression and expansion in the economy in the context of Pakistan in a longer period of time. Economic growth indeed 
has many controversial issues regarding the explanatory variables such as inflation. When it comes to the potential causes of wealth erosion, inflation will immediately come to mind (Balac, 2008). According to Barro (1995), inflation is the determinant of economic growth, which has been further explained that if there is a high inflation, then the level of investment will be reduced. Thus, the reduction in investment adversely affects economic growth.

According to Ang (2008), Malaysia needs to remain as a strong GDP growth to attract FDI inflows. According to Anwar and Sun (2011), FDI has a huge impact on economic growth in Malaysia. Based on the previous research, Herzer et al. (2008), have mentioned that there is a positive relationship between FDI and economic growth. Finally, the explanatory variable that affects economic growth is female labour force participation. The common result from research done by Bryant et al. (2004), concluded that by increasing the labour force participation of women, it increases the rate of economic growth. The above-mentioned factors or variables and many other factors can affect the economic growth but the present research consider the four variables that might affect the economic growth, the research investigated the following four variables.

2.2 Foreign direct investment (FDI)

Agrawalla and Tuteja (2007) foreign direct investments are commonly made in open economies, as opposed to tightly regulated economies, that offer a skilled workforce and above-average growth prospects for the investor. Foreign direct investment frequently involves more than just a capital investment. It may include the provision of management or technology as well. Foreign Direct Investment (FDI) stocks measure the total level of direct investment at a given point in time, usually the end of a quarter or over a year. Rahman and Salahuddin (2010) has been discussed the outward FDI stock is the value of the resident investors' equity in and net loans to enterprises in foreign economies. The inward FDI stock is the value of foreign investors' equity in and net loans to enterprises resident in the reporting economy. FDI stocks are measured in USD and as a share of GDP. FDI creates stable and long-lasting links between economies.

Alfaro (2004) examined the various links among foreign direct investment (FDI), financial markets, and economic growth. Falki (2009) examine the effect of FDI on Pakistan's economic development. Falki exercises the endogenous theory of growth in the analysis and regression tests, Falki research resulted the FDI has an inverse relationship with GDP of the country. Conversely, Adam and Tweneboah (2009), the economist from Ghana investigated a study on FDI effect on the market development of a country, the resulted suggested that FDI and the development of the stock market have a positive relationship, stock market will develop if the FDI is increased further. Similarly, the decrease will be the result of some factors including FDI.

\subsection{Liquidity and Size}

According to Kyle (1984) and Holmstrom et al. (1998), concluded that inside and outside knowledge to the investors is the function of how liquid id the stock market. Some studies reported that stock market liquidity and size is crucial for growth (Bencivenga et al., 1996; Levine, 1991). Previous studies use two measures of stock market development namely size and liquidity. size is denoted as market capitalization as a percentage of GDP. The assumption behind this measure is that overall market size 
is positively correlated with the ability to mobilize capital and diversify risk on an economy-wide basis. Liquidity is calculated as the value of shares traded on the stock market exchange divided by GDP. The total value traded ratio measures the organized trading of firm equity as a share of national output and therefore should positively reflect liquidity on an economy-wide basis. The total value traded ratio complements the market capitalization ratio: although a market may be large, there may be little trading. Enormous recent researches (Levine et al., 2000; Levine \& Zervos, 1998; Beck \& Levine, 2002; Aghion et al., 2005) have shown meaning full for the effect of different financial indicators summarizing stock market liquidity, size of the market and market capitalization on growth. Panel data has been used is that studies which are based on the World Bank databases (WDI \& GDF). Aghion et al., (2005) concluded and find support for significant economic convergence among economies of high liquidation.

Liquidity describes the degree to which an asset or security can be quickly bought or sold in the market without affecting the asset's price. Market liquidity refers to the extent to which a market, such as a country's stock market or a city's real estate market, allows assets to be bought and sold at stable prices. Cash is considered the most liquid asset, while real estate, fine art and collectables are all relatively illiquid. Share turnover is a measure of stock liquidity calculated by dividing the total number of shares traded over a period by the average number of shares outstanding for the period. The higher the share turnover, the more liquid the share of the company. Zhu and others (2002) showed that the Levine-Zervos results are not robust to alternative specifications because of the incomplete manner in which they control for outliers in their data. And they showed that when one properly controls for outliers, stock market liquidity no longer exerts any statistically observable influence on GDP growth

Levine (2003) focus on the ambiguous predictions about the relationship between stock market liquidity and economic growth. The paper presents cross-country evidence on the association between one measure of stock market liquidity and average economic growth rates over the period 1976 - 1993. The data suggest that there is a strong positive relationship between long-run economic growth rates and stock market liquidity. Amaral and Quintin (2007) asserted that the best use of stock market in a productive manner is the sign of economic growth. According to Aysan (2006), argued the growth volatility of country is the result of the high-level capital of unorganized and underdeveloped financial sector. The stock market development is the most important variable that resulted in the growth of the economy (Shahbaz et al., 2008). Sing and Odit (2008) describes the national output is the function of well-planned stock value traded.

Mawla (2011), aimed to test the relationship between stock market liquidity indicators and the economic growth represented by the growth rate of a group of Arab states from 1994 to 2007.The model adopted for testing the relationship is the simple linear regression model. It concluded that liquidity provided by the stock market doesn't have a significant effect on the economic growth of the sample countries

\subsection{Market Capitalization}

Market capitalization refers to the value of a company's outstanding shares, and can be calculated by multiplying the current stock price with shares outstanding Market capitalization reflects the theoretical cost of buying all of a company's shares, but usually is not what the company could be purchased for in a normal merger transaction. 
To estimate what it would cost for an investor to buy a company outright, the enterprise value calculation is more appropriate. Thus, market capitalization is a better measure of size than worth. That is, market capitalization is not the same as market value, which can generally only be assigned when the company is actually sold. Market capitalization is considered the biggest macro indicator for doing a country analysis which is defined as the value of listed shares divided by GDP and is a measure of the size of stock markets relative to the economy. Though market capitalization is not a universal indicator of predicting economic performance but has positive effect of financial development on economic growth. Many researchers have devoted a lot of time for finding this relationship in different countries. Few researchers previously done like Arestis et al. (2001), Buelens et al. (2006), Adjasi and Biekpe (2006), Enisan and Olufisayo (2009), Ake and Ognaligui (2010), Ikikii and Nzomoi (2013), and Haque (2013) predicted by their researchers that there is no significant positive impact on stock markets development and economic growth.

Also, Rousseau and Wachtel (2000) and Beck and Levine (2003) analyzed that stock market development is strongly correlated with the growth rate of real GDP per capita. These studies also found that stock market liquidity is a major stock market development variable that explains economic growth. However, most of these studies suffer from various statistical/ econometric weaknesses. In the research of Shahbaz 2008 , revealed that attaining the growth in the economy is the function of developing the stock market of a country. Petros (2009) explored a significant relationship between financial market development and economic growth. Specifically, Petros (2009) examined a time series data from 1991 to 2007 of Zimbabwe stock exchange by using the test like Auto-regressive Distributed Lag (ARDL).

El - Wassal in 2013 argued that many crucial functions that are incurred in the stock market are the sign of a better economic condition of a country, which also includes the cost of transaction and cost of monitoring. Bayer in 2014 investigated the link between these two variables in Turkey in the span of 1999 to 2013. In the research, the test which is used is Juseliuse Co-integration and demonstrate that stock market development affects the growth of the economy in long term. Naik and Padhi (2015) remarked that developing a financial market can contribute the economic growth and this is evidenced by a panel of 27 markets that are in emerging state. Some economist from past few years taking interest in the growing economies in Asia. 


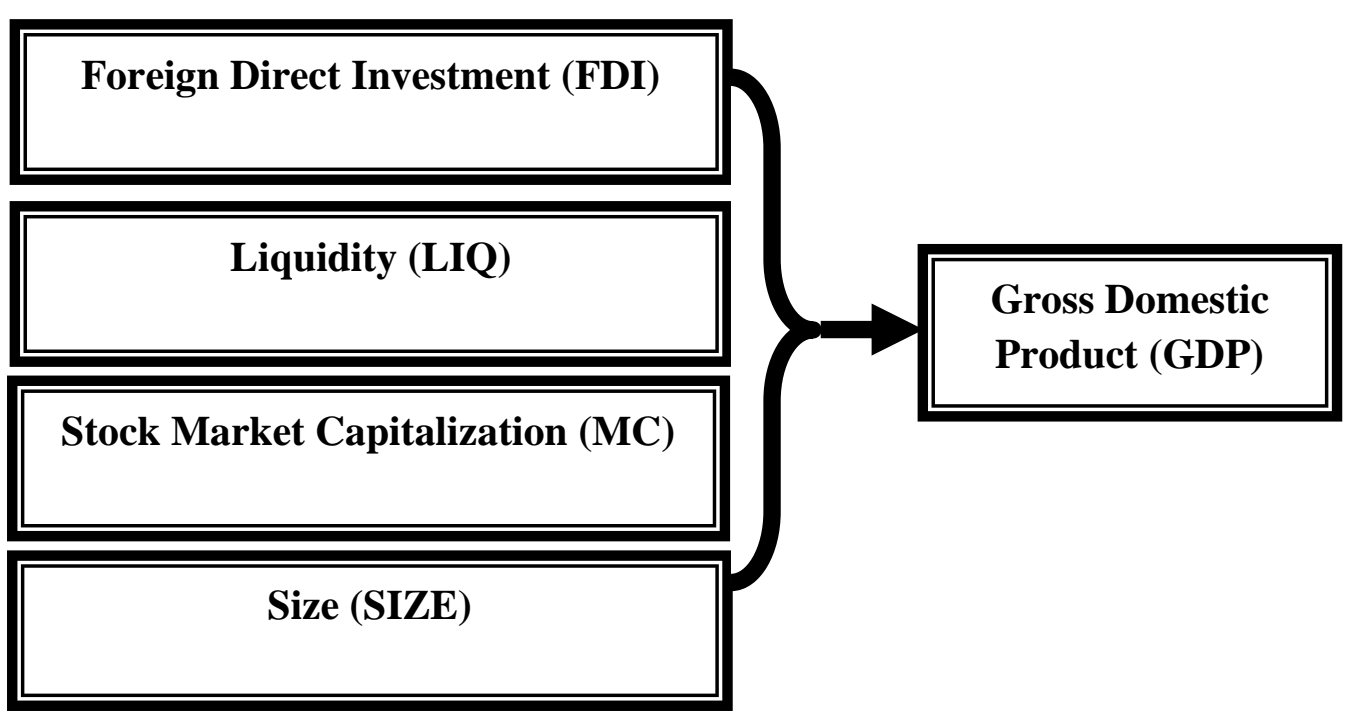

Figure 2.1 Conceptual Frame Work

\subsection{Research Hypothesis}

The alternative hypotheses of the study are:

$\boldsymbol{H}_{1}$ : DFDI has a significant effect on DGDP.

$\boldsymbol{H}_{2}:$ DLIQ has a significant effect on DGDP.

$\boldsymbol{H}_{3}$ : DSMC has a significant effect on DGDP.

$\boldsymbol{H}_{4}:$ DSIZE has a significant effect on DGDP.

\section{Research Methodology and Source of Data}

The current study will explore the effect of stock market development on the growth of the economy. The research includes a time series data from Pakistan and it summarizes the span of 2000 to 2017. The variables are used in the present research are gross domestic product, foreign direct investment, size, stock market capitalization, liquidity is the total value of the traded share, and Stock market capitalization of listed companies is the share price times the number of shares outstanding. The data for all the variables are drawn from "Economic Survey of Pakistan", "State Bank of Pakistan (SBP)"," Pakistan Stock Exchange (PSX)". For instance, FDI which is data for the selected time period will be obtained"from the official website of the Pakistani Board of Investment, Business and Finance Review and The Daily Jang Business Magazine. The facts and figures on stock market indicators namely 'size' and 'LIQ' will be figured out from various PSX bulletins and publication of Business Recorder.

\subsection{Statistical Tools}

The previous researchers have used different statistical tools like Ordinary Least Square regression (OLS), Auto-regressive Distributive Lag model (ARDL), Error Correction Model (ECM), and Co-integration etc. But the present research is based on OLS and Fully Modified OLS (FMOLS)which is also a part of Co-integration technique. The reason to use the above statistical technique is that the data used in the research is continuous data i.e. the predictor and explainatory variables are a continuous variable. Ordinary least-squares (OLS) regression is a generalized linear modeling technique that 
can also be applicable for modeling single response or multiple explanatory variables as well as categorical explanatory variables that are coded suitably. Ordinary least squares (OLS) or linear least squares is used for deducting the hidden parameter in the linear regression model. OLS select the parameters of a linear function of a set of explanatory variables by reducing the sum of the squares of the deviation and the observed dependent variable in the present dataset and those predicted by the linear function. From the previous researches it is known that application of simple OLS regression model does not capture the true relationship between time series variables due to the reasons of autocorrelation, heteroskedasticity, and endogeneity between lags and leads of the variables, so we need a modified regression approach to solve these issues and capture the true relationship between the given time series approach. The FMOLS technique applies Kernal estimators of the Nuisance parameters that affect the asymptotic distribution of the OLS estimator. For attaining asymptotic efficiency, this method confines least squares to account for serial correlation effects and test for the endogeneity in the regressors that result from the existence of Co-Integrating Relationships.

\subsection{Stationary}

The research is based on a time series data analysis. A momentous assumption is that the time series data is stationary. Usually, it is perceived that time series data is generated by a stochastic or random process. "A stochastic method is called to be stationary if its mean and variance are constant over time and the value of covariance in two-time periods hangs on the distance or lag between the two periods and not on the actual time at which the covariance is computed" (Gujarati,1995). A rational assumption of time series regression, a most frequently applied method is the stationarity in econometrics. A time series has stationarity if a shift in time doesn't cause a change in the shape of the distribution. Basic properties of the distribution like he mean, variance and covariance are constant over time. It needs that the variables put in the regression have their variances (standard deviations), covariance (autocorrelation), and means that are not dependent on time. A stationary series must not drift too distant from its mean. Usually, the postulate deviates (non-stationarity, i.e., random walk) and running such regression includes what they say a spurious regression. The available solution for facing this issue is assumed variables transformation.

\section{Random Walk (without Drift)}

Suppose $u_{t}$ is a white noise error term

with mean 0 and variance $\sigma^{2}$. Then the series $Y t$ is said to be a random walk if

$$
Y_{t}=Y_{t-1}+u_{t}
$$

Random Walk (with Drift)

$$
Y_{t}=\delta+Y_{t-1}+u_{t}
$$

Deterministic trend

$$
Y_{t}=\beta_{1}+\beta_{2 t}+u_{t}
$$


Random walk (with drift and deterministic trend)

$$
\boldsymbol{Y}_{t}=\boldsymbol{\beta}_{1}+\boldsymbol{\beta}_{2 t}+Y_{t-1}+\boldsymbol{u}_{t}
$$

Deterministic trend (with stationary AR (1) component)

$$
Y_{t}=\beta_{1}+\beta_{2 t}+\beta_{3} Y_{t-1}+u_{t}
$$

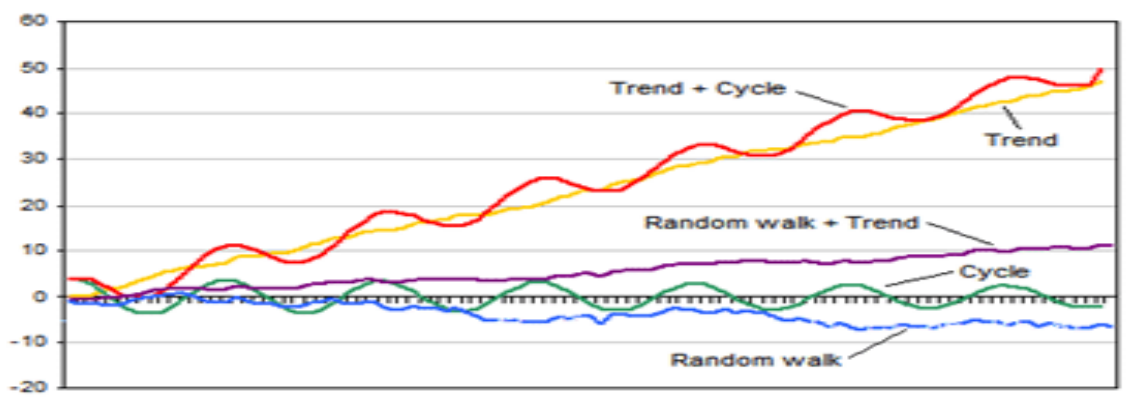

Figure 1: Non-stationary Behavior

3.3 Ordinary Least-Squares (OLS) and Fully Modified Ordinary Least-Squares (FMOLS):

Many different updated econometric methods are injected for examining the availability of a long-term link amid variables. Ordinary least-squares (OLS) regression is a generalized linear modeling technique that can also be applicable for modeling single response or multiple explanatory variables as well as categorical explanatory variables that are coded suitably. Ordinary least squares (OLS) or linear least squares is used for deducting the hidden parameter in the linear regression model. OLS select the parameters of a linear function of a set of explanatory variables by reducing the sum of the squares of the deviation amid the observed dependent variable in the present dataset and those predicted by the linear function.OLS Fully modified OLS will be used in this research but the focus and results will be based on FMOLS because the OLS is too basic for predicting the results.

The research adopted the FMOLS technique to analyze the link or bond between the independent variables (FDI, Liquidity, MC, size) and the dependent variables (GDP) in Pakistan. The FMOLS technique gives sound judgments for minute sample size and curbs for soundness of the conclusions. The FMOLS techniques basically presented as well as evolved by Philips and Hansen (1990) enable measuring a single co-integrating association including a composite of I (1). The FMOLS technique hold superiority on the EG method in innovating suitable correction to vanquish the inference hurdle in EG technique, therefore, the t-test for long-run judgments are reasonable (Himansu, 2007).

The fully modified ordinary least squares approach is also a time series specific regression approach. From the previous researches it is known that application of simple OLS regression model does not capture the true relationship between time series variables due to the reasons of autocorrelation, heteroskedasticity,and endogeneity between lags and leads of the variables, so we need a modified regression approach to solve these issues and capture the true relationship between the given time series approach. The FMOLS technique applies "Kernal estimators of the Nuisance parameters 
that affect the asymptotic distribution of the OLS estimator. For attaining asymptotic efficiency, this method confines least squares to account for serial correlation effects and test for the endogeneity in the regressors that result from the existence of Co-integrating Relationships" (Rukhsana \& Shahbaz, 2008).

\subsection{Econometric Model}

$$
G D P_{t}=C_{0}+C_{1} F D I_{t}+C_{2} S I Z E_{t}+C_{3} L I Q_{t}+C_{4} S M C_{t}+\mu_{i}
$$

Where the GDP $P_{t}$ is for per capita for fixed time period t, $F D I_{t}$ represents Foreign Direct Investment at time $\mathrm{t}, S I Z E_{t}$ equal to the total size of stock at time t, $L I Q_{t}$ denotes the traded shares total value derived as liquidity of stock market at time t, $S M C_{t}$ is stock market capitalization at time $\mathrm{t}$.

\section{Result and Analysis}

The raw data for the period of 2000 to 2016 were used to obtain our final objectives of the present research. In this section, the researcher used all those statistical tools which were helpful to match the desired objectives. The analysis of the present research given below:

Annual Data of Variables for Analysis (in Millions)

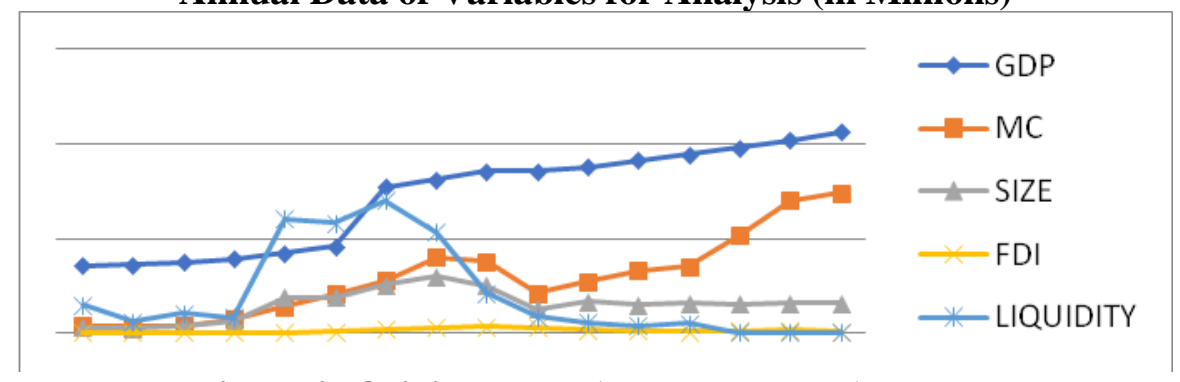

Figure 2: Original Data (Untreated Data) Results

The raw data of the period from 2000 to 2016 shows the above pattern which is processed by applying the statistical test like ADF which basic purpose is to make the data stationary.

\subsection{Unit Root Test Results}

The research used time series data which should be stationarity for better results, for that purpose unit root analysis is applied to analyze whether data is stationary or not. The study examined the data both on the level and on first difference followed by the process of comparing results. The researcher needs efficient results for their work, but researcher always faces a problem of non-stationarity in time series data. Now the question is how to remove the time effect from time series data, for the purpose of getting the better and efficient results. This problem can be checked by Augmented Dickey-Fuller test, the null hypothesis for this test is the series has unit root versus alternative hypothesis the series has no unit root. The first one can check all the variables at a level which are insignificant at 5\% level of significance which is not appropriate for further study, then checked by first difference all the variables become stationary at 5\% level of significance, now the first difference variables will be used for further analysis. 
Table -1: Augmented Dickey-fuller Test for Non-Stationary \& Stationary Data

\begin{tabular}{llllllll}
\hline \multicolumn{3}{c}{ Non- Stationary } & \multicolumn{5}{c}{ Stationary } \\
\hline & \multicolumn{3}{c}{ Level } & & \multicolumn{3}{c}{ First Difference } \\
\hline & ADF Test & $\begin{array}{l}\text { Critical } \\
\text { values }\end{array}$ & Probability & & ADF Test & Critical \\
values & Probability \\
\hline GDP & 1.989390 & -1.605026 & 0.9838 & DGDP & -2.561044 & -1.604392 & 0.0147 \\
FDI & -1.185999 & -1.604392 & 0.2037 & DFDI & -2.123854 & -1.604392 & 0.0405 \\
LIQ & -1.080794 & -1.605026 & 0.2401 & DLIQ & -4.926778 & -1.602074 & 0.0005 \\
MC & 1.981862 & -1.605026 & 0.9835 & DMC & -2.190310 & -1.604392 & 0.0320 \\
SIZE & -0.259752 & -1.605026 & 0.5755 & DSIZE & -3.267910 & -1.604392 & 0.0032 \\
\hline
\end{tabular}

The below table (2) shows the values of OLS applied on the original data which is not modified to first difference the coefficient value of each independent variable shows the relationship to the dependent variable whether it is positively correlated or negatively, LIQ is negatively correlated with that of GDP. T-Statistics identify the significance of individual variable, FDI is slightly higher than two, means FDI is significant and the rest variables are insignificant. Probability shows the significance values, all the variables are greater than 0.05 means all variable insignificant, if one can observe the value of R-square and adj R-square are too higher which gives the wrong direction about the data, this indicates that there is some stationarity and econometric problem, because if maximum variables shows the nature of insignificant and then its not possible to provide such a high value of $\mathrm{R}$-square. In simple word the results are not sound of this original data, the data has to be modified for further study and predictions.

Table - 2: Co-integration (OLS) test results: (Original Data)

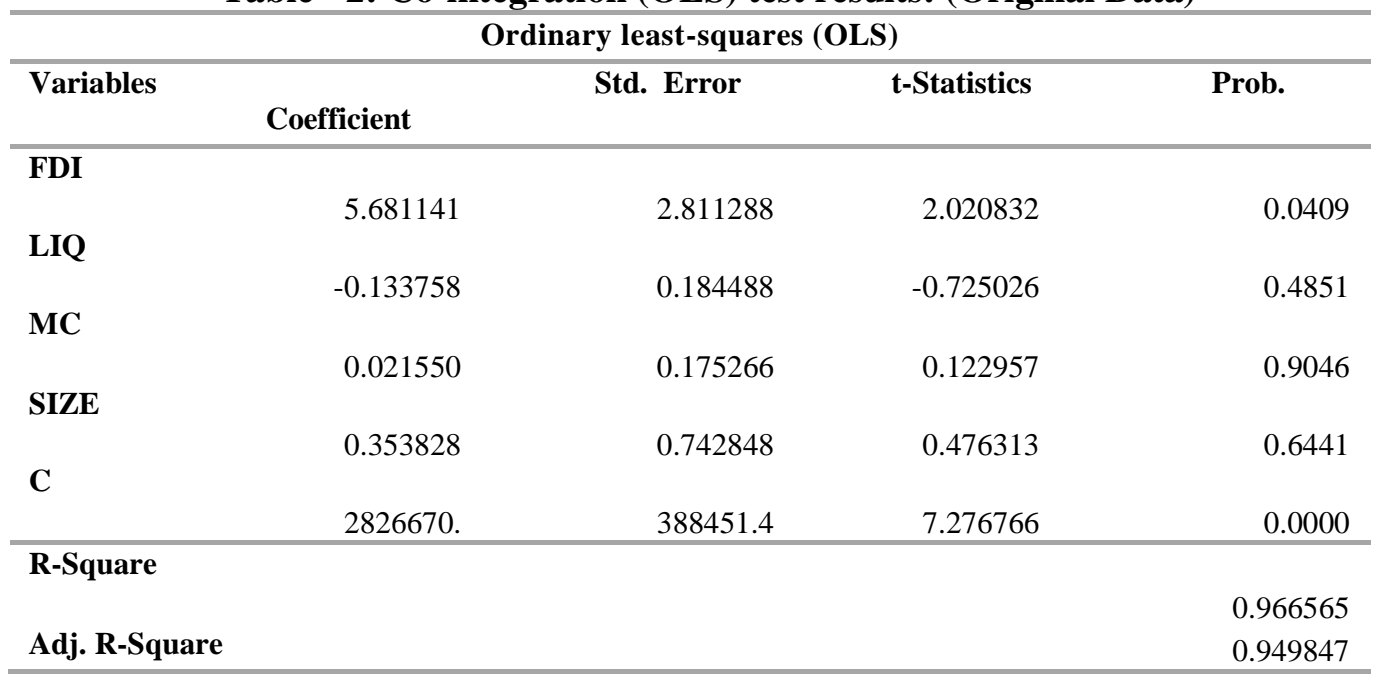


The below table (3) shows the values of OLS applied on the data which is modified to first difference the coefficient value of each independent variable show the relationship to the dependent variable whether it is positively correlated or negatively correlated, DLIQ and DMC is negatively correlated with DGDP, means if the DLIQ and DMC are increased the DGDP will decrease, which apply that DLIQ and DMC are inversely related to DGDP. T-Statistics identify the individual variable significance, DFDI is higher than two, means DFDI is significant and the rest variables are insignificant.

Now, if compare the first difference result with the previous result, clearly observed the difference between the values of R-square and Adj R-square. In this case the value of $\mathrm{R}$-square is decrease due to eliminated the time effect from the selected variable, the value of R-square is decreased from $96.62 \%$ to $53.47 \%$ and the value of Adj R-square $94.98 \%$ to $27.62 \%$, this indicates that if the number of significant variables is minimum and the role of variables are not justified then the value of Adj $\mathrm{R}$-square will not be increase. In the below table it is clear that, the contribution of these variables is not appropriate that's the reason for the minimum value of Rsquare and Adj R-square.

Table - 3: Co-integration (OLS) test Results :( First Difference Data)

\begin{tabular}{|c|c|c|c|c|}
\hline \multicolumn{5}{|c|}{ Ordinary least-squares (OLS) } \\
\hline Variables & Coefficient & Std. Error & t-Statistics & Prob. \\
\hline DFDI & 10.08031 & 3.551090 & 2.838653 & 0.0194 \\
\hline DLIQ & -0.046823 & 0.151794 & -0.308461 & 0.7648 \\
\hline DiNC & -0.793636 & 0.418965 & -1.894279 & 0.0907 \\
\hline DSIZE & 1.209708 & 0.714150 & 1.693913 & 0.1245 \\
\hline$C$ & -291750.5 & 439946.0 & -0.663151 & 0.5239 \\
\hline R-Square & & & & 0.534717 \\
\hline $\begin{array}{l}\text { Adj. R- } \\
\text { Square }\end{array}$ & & & & 0.276226 \\
\hline
\end{tabular}

The below table (4) shows the values of FMOLS applied on the original data which is not modified to first difference the coefficient value of each independent variable shows the relationship to the dependent variable whether it is positively correlated or negatively correlated, LIQ is negatively correlated with that of GDP, means if the LIQ is increased the GDP will decrease, which apply that LIQ is inversely related to GDP. The Standard error which is closer to zero, indicates that the dispersion among the values of different year is minimum. All the variables standard errors are close to zero means all the variables shows the minimum dispersion. T-Statistics identify the individual variable significance, FDI value is higher than two, means that FDI is significant and the rest variables are insignificant. Now, again the values of R-square and Adj R-square are too high, in this case also shows the wrong direction about the analysis. This analysis shows some stationarity and econometric problem, this may lead to wrong decision and predication. 
Table - 4 Co-integration (FMOLS) test results: (Original Data)

\begin{tabular}{lrrrr}
\hline \multicolumn{5}{c}{ Method: Fully Modified Least Squares (FMOLS) } \\
\hline Variables & Coefficient & Std. Error & \multicolumn{1}{c}{ t-Statistics } & \multicolumn{1}{l}{ Prob. } \\
\hline FDI & 5.743816 & 1.816000 & 3.162895 & 0.0115 \\
LIQ & -0.167157 & 0.119066 & -1.403903 & 0.1939 \\
MC & 0.009419 & 0.117958 & 0.079848 & 0.9381 \\
SIZE & 0.455946 & 0.482111 & 0.945729 & 0.3690 \\
C & 2790841. & 302626.0 & 9.222080 & 0.0000 \\
\hline R-Square & & & & 0.966755 \\
Adj. R-Square & & & & 0.948285 \\
\hline
\end{tabular}

The Fully Modified Ordinary Least Square method (FMOLS) primarily proposed by Phillip and Hansen (1990). The technique engages the semi-parametric correction to exclude the long-run correlation between the co-integrating equation and the innovations. The coefficient value of each independent variable shows the relationship to the dependent variable whether it is positively correlated or negatively. The DFDI unveils that it has positively correlated with that of DGDP means if DFDI increases by PKR 1 Million the DGDP will increase by PKR 10.62 Million,similarly, the DSIZE also show a positive relationship with DGDP, that is if the size increases the DGDP will also increase and if it decreases the DGDP will also decrease. Conversely, the DLIQ and DMC show an inverse relationship with DGDP. The Standard error which is closer to zero, shows minimum dispersion among the values of different years. All the variables standard errors are close to zero means all the variables gives the minimum dispersion. T-Statistics shows the significance of a single variable, the variable is significant if the $t$ value is greater than 2, by taking the absolute values three variable shows the significance that is DFDI, DMC and DSIZE with their values of 5.19, 3.67 and 3.55 respectively while DLIQ value is less than 2 means it is insignificant.

Also, the value of R-square and Adj R-square are $53.21 \%$ and $23.97 \%$ respectively, the value of R-square shows 53.215 of variation is explain due to the independent variables, which are included in the model and the rest of variation is unexplained due to the error term, and the Adj R-square value is $23.97 \%$ represent that there are very few important variables included in the model, there is so many variables need to be include in the model for better result. Now this model is overall significant at 5\% level, mean that FMOLS analysis is better than OLS for predication.

Table - 5: Co-integration (FMOLS) test results: (First Difference)

\begin{tabular}{|c|c|c|c|c|}
\hline \multicolumn{5}{|c|}{ Method: Fully Modified Least Squares (FMOLS) } \\
\hline Variables & Coefficient & Error & $\begin{array}{c}\mathrm{t}- \\
\text { Statistics }\end{array}$ & Prob. \\
\hline DFDI & 10.62715 & 2.044851 & 5.197027 & 0.0008 \\
\hline DLIQ & -0.090809 & 0.082196 & -1.104792 & 0.3014 \\
\hline DMC & -0.868184 & 0.236404 & -3.672459 & 0.0063 \\
\hline DSIZE & 1.402940 & 0.394426 & 3.556916 & 0.0074 \\
\hline $\mathbf{C}$ & -469179.8 & 295200.8 & -1.589358 & 0.1506 \\
\hline R-Square & & & & 0.532125 \\
\hline
\end{tabular}




\section{Discussion and Conclusion}

Financial markets show their significance rapidly, therefore, researchers are interested in finding the "impact of stock market development on economic growth". The current investigation is an effort to review the linkage of stock market development and economic growth by taking the first difference of size (DSIZE) and liquidity (DLIQ) of Pakistan Stock Exchange (PSX) along with first difference of Foreign Direct Investment (DFDI) and Stock Market Capitalization (DMC) of Pakistan as independent variables. The impact of listed variables is tested on first difference of Gross Domestic Products (DGDP) as a dependent variable of economic growth for the period of 2000 to 2017. The research utilizes Ordinary Least Squares (OLS) and Fully Modified Ordinary Least Squares method (FMOLS) for the time series data for Pakistan. The trials of time series properties reveal that the variables are integrated of order one, I (1) and co-integrated which facilitates the use of the FMOLS. The FMOLS results disclosed that the DFDI is a significant variable capable of explaining economic growth and that there exists a positive relationship between DFDI and DGDP. That is, a 1 Million Rupees increase in DFDI brings about 10.62715 Million rupees rise in economic growth. Similarly, DMC and DSIZE positive effect on the DGDP because the significance level is less than 5\% but It can be said that DLIQ has no significant effect on economic growth.

Probability (p-values) shows, the significance of values and gives the reason to accept or reject the hypothesis. The first Null Hypothesis $\left(\mathrm{H}_{0}\right)$ is "DFDI has no significant effect on DGDP" which shows the significant effect on DGDP because the probability value is 0.0008 which is less than 0.05. Alternative this means that alternative hypothesis is accepted. The second Null hypothesis is "DLIQ has no significant effect on DGDP" which is accepted keeping in mind the value of DLIQ which is greater than 0.05 , therefore the Alternative hypothesis $\left(\mathrm{H}_{2}\right)$ is rejected, means DLIQ has no effect on DGDP. Similarly, $\mathrm{H}_{3}$ and $\mathrm{H}_{4}$ that are DMC significant effect on DGDP and DSIZE have asignificant effect on DGDP are accepted because their null hypothesis is rejected due to the value of significance fall below 0.05 . Additionally, the value of $\mathrm{R}$ square is $53 \%$ signifying a good fit. This result emphasizes the important role of all independent variables (Except liquidity) in economic growth in Pakistan.

\section{Alternative Hypothesis}

Accepted/Rejected

H1: DFDI has a significant effect on DGDP.

H2: DLIQ has a significant effect on DGDP.

Accepted

H3: DMC has a significant effect on DGDP.

Rejected

H4: DSIZE has a significant effect on DGDP.

Accepted

Accepted

The hypothesis shows that except liquidity all independent variable of the stock market has significant role in the economic growth. To predict the ups and downs and better forecasting of the market and economy the research used recent data for analysis. the present research is contrasted with the previous research processes by using different analysis techniques and recent financial data.

\subsection{Limitation of the Study}

Applying the econometric method for analysis of Pakistan economic aggregate is not likely to produce the reliable results due to a wide range of data deficiencies. Data on 
important aggregate variables are available only on yearly basis. This study is based on the data for the period of fifteen years from 2000 to 2015. It tries to find out the relationship between stock market and economic growth. For this purpose, the period of fifteen years is not adequate to form any kind of relationship but an attempt has been made in that direction, secondly the study is based on secondary sources of data, the authenticity of which may be questioned, as there are variations in some data variable across the sources. The present study recommends that policymakers can build an economic strategy for the attraction of the Foreign Direct Investment and trade openness by exploring their major determinants and also focus on the positive relationship variables.

\subsection{Recommendations}

As is found by the numerous research works, including this particular one, the study has reached to the following recommendations are suggested.

The Securities Board of Pakistan has the responsibility of regulating the entire securities market in Pakistan. To make the Board effective, the number of staff should be adequate and properly trained in all aspects of the securities market. It should bring new and emerging stock market regulatory regimes to match international standards.

Strong provisions via specific laws should be made to protect the rights of the investors. Regulatory agencies should make favorable environment for online trading, which make PSX transaction decentralized.

Maximum possible information should be made available to the investors at minimum possible costs.

The timely and regular discourse of the information should be made necessary for the participating firms. Provisions should be made so as to necessitate the organizations to disclose their financial data at least quarterly.

Management of the listing and de-listing of the firms should be made effective with the help of specific criteria.

Market makers and investment bankers should be encouraged to participate in the stock market.

Specific provisions should be made to attract the foreign portfolio investment in the domestic market.

Ways of the transaction should be rectified and modified via automated quotation and appropriate technology.

If the necessary measures are taken towards making the Pakistan stock market more efficient, not only investors and participating firms but the whole economy is likely to benefit. Since, the efficiency of the market may be the cause for the efficiency of the economy; this goal should be pursued by concerning authorities more vigorously and seriously. Finally, there is a lot of scope for research in this particular field. Finding the contribution of stock market to the economy and research study in this area are new phenomena. Therefore, in case of Pakistan, as well, the extended and comprehensive study in this field will be just as timely and appropriate. Even, this particular study can be extended by including more and more specific variables and designing the research ore appropriately. Another aspect of future research may be not merely the relationship between stock market and economic growth variables but mainly focus on the channels through which the stock market are able to influence the growth process positively. The 
government should remove impediments to stock market development in the form of tax, legal and regulatory barriers because they are sometimes disincentives to investment, should invest more and develop the nation's infrastructure in order to create an enabling environment for businesses to grow, increase the productivity and efficiency, and the rate of returns of firms, should employ appropriate trade policies that promote the inflow of international capital and foreign investment so as to enhance the production capacity of the nation, and should strengthen the capacity of the Pakistan Stock Exchange so as to check and prevent sharp practices by market operators in order to safeguard the interest of shareholders.

\section{References}

Abdul-Khaliq, S. (2013). The impact of stock market liquidity on economic growth in Jordan. European Journal of Business and Management, 5(30), 154-158.

Adjasi, C. K., \& Biekpe, N. B. (2006). Stock market development and economic growth: The case of selected African countries. African Development Review, 18(1), 144-161.

Afza, T., \& Nazir, M. S. (2007). Economic competitiveness and human resource development: An FDI perspective. Pakistan Economic and Social Review, 167-180.

Agrawalla, R. K., \&Tuteja, S. K. (2007). Causality between stock market development and economic growth: a case study of India. Journal of Management Research, 7(3), 158.

Ahmad, Z., Khan, A. A., \& Tariq, A. (2012). Stock market development and economic growth: A comparative study of Pakistan and Bangladesh. African Journal of Business Management, 6(8), 2985.

Antunes, A. R., \& Cavalcanti, T. V. D. V. (2007). Startup costs, limited enforcement, and the hidden economy. European Economic Review, 51(1), 203-224.

Arno, P. S., Levine, C., \&Memmott, M. M. (1999). The economic value of informal caregiving. Health Affairs, 18(2), 182-188.

Azam, M., Haseeb, M., Samsi, A. B., \& Raji, J. O. (2016). Stock market development and economic growth: Evidence from Asia-4 Countries. International Journal of

Economics and Financial Issues, 6(3).

Bashier, A. A. A., \&Wahban, A. N. (2013). The determinants of employment in Jordan: A time series analysis. International Review of Management and Business Research, 2(4), 927.

Bashier, A. A., \& Siam, A. J. (2014). Immigration and economic growth in Jordan: FMOLS approach. Int J HumanitSoc Sci Educ, 1(9), 85-92.

Beck, T., \& Levine, R. (2004). Stock markets, banks, and growth: Panel evidence. Journal of Banking \& Finance, 28(3), 423-442.

Bencivenga, V. R., Smith, B. D., \& Starr, R. M. (1996). Liquidity of secondary capital markets: Allocative efficiency and the maturity composition of the capital stock. Economic Theory, 7(1), 19-50.

Bengoa, M., \& Sanchez-Robles, B. (2003). Foreign direct investment, economic freedom and growth: new evidence from Latin America. European journal of political economy, 19(3), 529-545. 
Boldeanu, F. T., \& Constantinescu, L. (2015). The main determinants affecting economic growth. Bulletin of the Transilvania University of Brasov. Economic Sciences. Series $V, 8(2), 329$.

Carp, L. (2012). Can stock market development boost economic growth? Empirical evidence from emerging markets in Central and Eastern Europe. Procedia Economics and Finance, 3, 438-444.

Carp, L. (2012). Can stock market development boost economic growth? Empirical evidence from emerging markets in Central and Eastern Europe. Procedia Economics and Finance, 3, 438-444.

Enisan, A. A., \&Olufisayo, A. O. (2009). Stock market development and economic growth: Evidence from seven sub-Sahara African countries. Journal of Economics and Business, 61(2), 162-171.

Falki, N. (2009). Impact of foreign direct investment on economic growth in Pakistan. International Review of Business Research Papers, 5(5), 110-120.

Greenwood, J., \& Jovanovic, B. (1990). Financial development, growth, and the distribution of income. Journal of political Economy, 98(5, Part 1), 1076-1107.

Gudaro, A. M., Chhapra, I. U., \& Sheikh, S. A. (2010). Impact of foreign direct investment on economic growth: A case study of Pakistan. Journal of Management and Social Sciences, 6(2), 84-92.

Holmström, B., \& Tirole, J. (1993). Market liquidity and performance monitoring. Journal of Political Economy, 101(4), 678-709.

Ikikii, S. M., \&Nzomoi, J. N. (2013). An analysis of the effects of stock market development on economic growth in Kenya. International Journal of Economics and Finance, 5(11), 145.

Khan, K., \& Ahmed, I. (2015). Impact of Stock Prices on Macroeconomic Variables: Evidence from Pakistan. KASBIT Journal of Management \& Social Science, 8(1), 42-59.

Khan, M. A. (2008). Financial development and economic growth in Pakistan: evidence based on autoregressive distributed lag (ARDL) approach. South Asia Economic Journal,9(2), 375-391.

Levine, R. (1991). Stock markets, growth, and tax policy. The Journal of Finance, 46(4), 1445- 1465.

Levine, R. (1997). Financial development and economic growth: views and agenda. Journal of economic literature, 35(2), 688-726.

Levine, R., \& Renelt, D. (1992). A sensitivity analysis of cross-country growth regressions. The American economic review, 942-963.

Levine, R., \& Zervos, S. (1998). Stock markets, banks, and economic growth. American economic review, 537-558.

Levine, R., \& Zervos, S. (1998). Stock markets, banks, and economic growth. American economic review, 537-558.

Levine, R., \& Zervos, S. J. (1993). What have we learned about policy and growth from cross- country regressions? The American Economic Review, 83(2), 426-430.

Mishkin, F. S. (2001). The transmission mechanism and the role of asset prices in monetary policy (No. w8617). National bureau of economic research. 
Nazir, M. S., Nawaz, M. M., \& Gilani, U. J. (2010). The relationship between economic growth and stock market development. African Journal of Business Management, 4(16), 3473.

Nishat, M., \&Saghir, A. (1991). The Stock Market and Pakistan Economy- 196487. Savings and Development, 131-146.

North, D. C. (1991). Institutions. Journal of economic perspectives, 5(1), 97-112.

Nosheen, M. (2013). Impact of Foreign Direct Investment on Gross Domestic Product. World Applied Sciences Journal, 24(10), 1358-1361.

Obstfeld, M. (1994). Evaluating risky consumption paths: the role of intertemporal substitutability. European economic review, 38(7), 1471-1486.

Odit, M. P., \&Chittoo, H. B. (2008). Does financial leverage influence investment decisions? The case of Mauritian firms. Journal of Business Case Studies, 4(9), 49-60.

Oskooe, S. A. (2010). Emerging stock market performance and economic growth. American Journal of Applied Sciences, 7(2), 265.

Rahman, M. M., \& Salahuddin, M. (2009, September). The determinants of economic growth in Pakistan: does stock market development play a major role? In Proceedings of the $38^{\text {th }}$ Australian Conference of Economists (ACE 2009) (pp. 1-22).

Shahbaz, M., Ahmed, N., \& Ali, L. (2008). Stock market development and economic growth: ARDL causality in Pakistan. International Research Journal of Finance and Economics, 14(1), 182-195.

Shahbaz, M., Ahmed, N., \& Ali, L. (2008). Stock market development and economic growth: ARDL causality in Pakistan. International Research Journal of Finance and Economics, 14(1), 182-195.

Shahbaz, M., Ahmed, N., \& Ali, L. (2008). Stock market development and economic growth: ARDL causality in Pakistan. International Research Journal of Finance and Economics, 14(1), 182-195.

Were, M. (2015). Differential effects of trade on economic growth and investment: A cross-country empirical investigation. Journal of African Trade, 2(1-2), 71-85.

Zhu, A., Ash, M., \& Pollin, R. (2004). Stock market liquidity and economic growth: A critical appraisal of the Levine/Zervos model. International Review of Applied Economics, 18(1), 63-71. 